\title{
Inferring Species Trees from Gene Trees: A Phylogenetic Analysis of the Elapidae (Serpentes) Based on the Amino Acid Sequences of Venom Proteins
}

\author{
Joseph B. Slowinski, ${ }^{*, 1}$ Alec Knight, $\dagger$ and Alejandro P. Rooneył
}

* Department of Biological Sciences, Southeastern Louisiana University, Hammond, Louisiana 70402; †Department of Biology, Sul Ross State University, Alpine, Texas 79832; and ¥Department of Veterinary Pathobiology, Texas A\&M University, College Station, Texas 77843

Received December 6, 1996; revised April 30, 1997

Toward the goal of recovering the phylogenetic relationships among elapid snakes, we separately found the shortest trees from the amino acid sequences for the venom proteins phospholipase $A_{2}$ and the short neurotoxin, collectively representing 32 species in 16 genera. We then applied a method we term gene tree parsimony for inferring species trees from gene trees that works by finding the species tree which minimizes the number of deep coalescences or gene duplications plus unsampled sequences necessary to fit each gene tree to the species tree. This procedure, which is both logical and generally applicable, avoids many of the problems of previous approaches for inferring species trees from gene trees. The results support a division of the elapids examined into sister groups of the Australian and marine (laticaudines and hydrophiines) species, and the African and Asian species. Within the former clade, the sea snakes are shown to be diphyletic, with the laticaudines and hydrophiines having separate origins. This finding is corroborated by previous studies, which provide support for the usefulness of gene tree parsimony. $\odot 1997$ Academic Press

\section{INTRODUCTION}

The family Elapidae is a major group of venomous snakes containing nearly 300 species in 62 genera (Golay et al., 1993; herein we use Elapidae in the broad sense to include both terrestrial and marine species, whereas Golay et al. place the marine species in the separate family Hydrophiidae). Traditionally, the family Elapidae has included front-fanged snakes with relatively immobile maxillae, i.e., proteroglyphs. However, there have been two challenges to the monophyly of the Elapidae (sensu lato) within the last three decades. McDowell (1968) argued for the removal from

\footnotetext{
${ }^{1}$ Current address: Department of Herpetology, California Academy of Sciences, Golden Gate Park, San Francisco, California 941184599. Fax: 415-750-7013; E-mail: jslowinski@calacademy.org.
}

the Elapidae and transfer to the Colubridae of the two species of H omoroselaps. Subsequently, Savitzky (1978) argued that New World coral snakes were allied more closely with certain South American colubrids than to other proteroglyphs. Savitzky's conclusions, however, were disputed on the basis of immunol ogical (Cadleand Sarich, 1981) and morphological (McCarthy, 1985) data. Recently, Underwood and Kochva (1993), in a phylogenetic analysis of morphological characters in representatives of Atractaspis, Homoroselaps, African aparallactine colubrids, African elapids, and the South American colubrids Apostolepis and Elapomorphus, found support for a relationship between Homoroselaps and elapids and returned Homoroselaps to that family. Hence, the family Elapidae is currently understood to constitute a monophyletic group containing all proteroglyphs.

McDowell (1970), in an examination of morphological characters, concluded that elapids fall into two groups: the palatine draggers and palatine erectors. Palatine draggers include Australasian terrestrial elapids (except Parapistocalamus) and hydrophiine sea snakes. In these species, the palatine acts as an anterior extension of the pterygoid, remaining horizontal even when the maxilla is erected (McDowell, 1970). The palatine erectors include terrestrial African, Asian, and American elapids, the marine Laticauda, and Parapistocalamus. I $n$ these species, the palatine is er ected along with the maxilla during protraction of the palate (McDowell, 1970). McDowell's hypothesis was used in the snake classification of Smith et al . (1977), who divided Elapidae sensu lato into Elapidae sensu strictoand Hydrophiidae for the palatine erectors and draggers, respectively.

There have been several molecular phylogenetic studies of elapids (reviewed under Discussion), but these studies have examined only limited numbers of taxa. Because of the extensive efforts over the past two decades by biologists studying the biochemistry and pharmacology of snake venoms, dozens of amino acid sequences of snake venom proteins are currently avail- 
able in molecular databases. Thus, elapid venom proteins offer a potentially valuable data source for comprehensive studies of elapid phylogeny. For the present study, we chose the venom proteins phospholipase $A_{2}$ $\left(P L A_{2}\right)$ and short neurotoxin (NXS) because of the large number of sequences available.

\section{Elapid Venom Proteins}

Phospholipase $A_{2}$ (PLA $;$; EC 3.1.1.4) is an enzyme that catalyzes the $\mathrm{Ca}^{2+}$-dependent hydrolysis of the 2-acyl ester bond of 3-sn-phosphoglycerides (De Haas and Van Deenen, 1961). Davidson and Dennis (1990) considered the evolution of PLA $\mathrm{A}_{2} \mathrm{~S}$ in snakes and mammals and hypothesized that a duplication event preceding the divergence of reptiles and mammals gave rise to Types I and II PLA ${ }_{2}$ S (Heinrikson et al., 1977), which differ in the configuration of disulfide bridges. In mammals, Type I $\mathrm{PLA}_{2} \mathrm{~S}$ are secreted in the pancreas, whereas Type II $\mathrm{PLA}_{2} \mathrm{~S}$ are strictly intracellular. In snake venom glands, only the former are expressed in elapids, whereas only the latter are expressed in viperids. Within elapids, Davidson and Dennis postulated a further gene duplication event which gave rise to Types IA and IB PLA ${ }_{2} S$. The majority of sequenced elapid $\mathrm{PLA} \mathrm{A}_{2} \mathrm{~S}$ are from the former group. Type IA PLA ${ }_{2} \mathrm{~S}$ can be diagnosed by the derived loss of the "pancreatic loop," a five residue stretch deleted from the middle of the enzyme. In this study, Type IB sequences from Oxyuranus scutellatus and Pseudonaja textilis were employed as the outgroup sequences for phylogenetic analysis of Type IA PLA ${ }_{2}$ S.

Short neurotoxins are 60-62 amino acid residues long and are part of a group of related elapid venom proteins that also includes long neurotoxins and membranetoxins (Karlsson, 1979). Pharmacologically, short neurotoxins bind to acetylcholine receptors, thereby preventing the depolarizing action of acetylcholine (Karlsson, 1979). A previous study (Strydom, 1979) suggests that NXSs are monophyletic relative to the long neurotoxins and membrane toxins.

Several studies have previously considered elapid $\mathrm{PLA}_{2} \mathrm{~S}$ (e.g., Dufton and Hider, 1983; Tamiya, 1985; Davidson and Dennis, 1990; Kostetsky et al., 1991) and NXSs (e.g., Tamiya, 1985) in a phylogenetic context, but these studies examined only a subset of the taxa now available.

\section{Inferring Species Trees from GeneTrees}

There are two levels of error possible in the reconstruction of species trees from molecular sequences: first, a gene tree for a series of molecular sequences will be incorrectly inferred if there is sufficient random or systematic error (Swofford et al., 1996), and second, even if a gene tree is correctly inferred, the phenomena of deep gene coalescence, gene duplication, and lateral
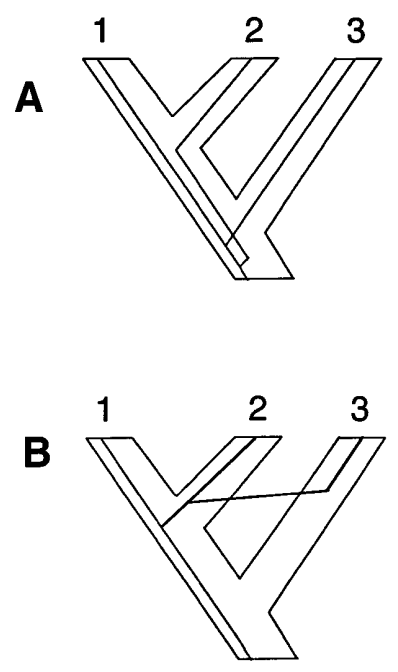

FIG. 1. Examples of gene trees embedded in species trees showing the sources of gene tree/species tree conflict. The tree in A shows the general phenomenon of sequence lineages coalescing prior to the ancestor of the species from which the sequences were sampled. In this case, the sequences sampled from species 1 and 2 coalesce prior to the ancestor of species 1 and 2 . This provides a window of opportunity for the sequence lineage from 3 to coal esce after the 1, 2, coal escence, leading to a gene tree incongruent with the species tree. This phenomenon can occur in two specific ways: first, the alleles at a single locus can fail to coalesce within the ancestor of the species from which they were sampled, a situation termed deep coalescence; or second, a gene can duplicate, followed by a failure of some of the descendant gene copies to be sampled. I n the latter case, genes 1 and 2 would be considered paralogous. Because of the expectation of descendant sequences from each duplication event, the two types of phenomena necessarily are analyzed differently (see Fig. 2). Tree B shows an example of lateral transfer, wherein a gene lineage with its ancestry in species 2 is transferred to species 3, leading to conflicting gene and species trees. This can occur in several ways, including hybridization between species and viral transfer of genes between hosts.

gene transfer (Fig. 1) can produce a gene tree different from the true species tree (Goodman et al., 1979; Avise et al., 1983; Pamilo and Nei, 1988; Doyle, 1992). In the following discussion, we assume that the terminal sequences of a gene tree have shared only one history and, further, that this history has been correctly inferred. A deep gene coalescence (ancestral polymorphism) is a coalescent event for a set of sequences at a single locus that preceded the ancestor of the species possessing the sequences. A deep coalescence ( $F$ ig. 1A) can produce conflict between a gene tree and the species tree because there is a window of opportunity for a sequence from a less related species to coalesce with one of the descendant sequences of the deep coalescence. Gene duplication (Fig. 1A) produces conflict that is analogous to deep coalescence because paralogous sequences are sequences that coalesced prior to the ancestor of the species from which they were sampled. Of course, the evolutionary dynamics of maintaining duplicated genes are different from those of maintaining multiple alleles at a locus, which are in 
direct competition. Nevertheless, without additional information (beyond observed conflict between a gene and species tree), it is impossible to distinguish be tween gene duplications and deep coalescences. Deep coalescences and gene duplications, however, are only part of the problem; therest of the problem involves our failure to sample sequences that have or might have descended from the ancestral sequences. For example, the conflict between gene and species trees due to sampling paralogous sequences from the two loci of a duplicated gene would disappear if sequences from both loci were sampled in all the species. Lateral gene transfer (Fig. 1B) includes phenomena such as hybridization between species, which obscures species phylogeny because sequences from one species may introgress into another species.

Faced with conflict among gene trees, the obvious question is: How should the species tree be inferred? One of the most commonly used strategies for inferring species phylogenies from multiple genes is the combined-data approach (Kluge, 1989), which works by concatenating all available gene sequences for a set of species into a single, composite matrix for analysis. Several authors have argued that the combined-data approach is not appropriate for genes with different histories (Bull et al., 1993; De Queiroz et al., 1995). Three specific reasons can beidentified. First, if there is sequence polymorphism within species, it is not obvious how this can be incorporated into a combined matrix: for species $X$, which sequences from gene $A$ should be combined with which sequences from gene $B$ ? Second, the distinction between homoplasy and gene tree/species tree conflict is ignored (Page and Charleston, 1997). For example, if a gene tree is (AB)C and the true species tree is $(A C) B$, then any substitutions occurring along the branch of descent leading to (AB) on the gene tree will be interpreted as homoplasy in the context of the species tree, even though they are not homoplasies at all. Third, and perhaps most important, because the nucleotides of a given gene share the same history (assuming no recombination; see bel ow), a gene phylogeny represents only a single character of the species phylogeny (Doyle, 1992), regardless of the number of nucleotides that compose that gene. Or to put it another way: genes with different histories are independent estimators of a species phylogeny, but within each gene the nucleotides are not independent estimators of the species phylogeny (Miyamoto and Fitch, 1995). To illustrate the problem, consider constructing a combined matrix from two gene sequences where one gene has twice the number of nucleotides. In this situation, we are giving that gene's history twice the weight. However, there is no a priori reason for weighting one gene's history more than another when inferring a species phylogeny.

This is not to say that the combined-data approach is never applicable; it is, but only under the restricted condition that a series of genes has the same bifurcating history. In this situation, it is probably desirable to combine the data because of the property of statistical consistency (Huelsenbeck et al., 1996), which ensures that the estimated tree converges on the true tree with ever-increasing numbers of characters. (However, phylogenetic consistency requires certain assumptions of the evolutionary process that generated the data.) Several tests have been proposed for the null hypothesis that two data sets represent character samples from the same phylogeny (reviewed by Huelsenbeck et al., 1996).

Because the nucleotides (or amino acids) from genes with different histories cannot becombined for phylogenetic analysis, several authors have proposed alternative methods for inferring species trees from gene trees based on treating each gene tree as the basic datum. Doyle (1992) and Ragan (1992) suggested recoding each gene phylogeny into parsimony characters, an approach that Ragan termed "matrix representation of trees." The resulting series of characters can then be analyzed to find the minimum-length species phylogeny. This approach, however, is flawed because homoplasy in this context has no obvious biological meaning (Rodrigo, 1993; Page, 1994a). When an extra step occurs for a character (gene tree), it is not clear just what that extra step means. Furthermore, polymorphism cannot be accommodated by this method.

De Queiroz (1993) advocated the use of consensus trees for inferring species trees in the face of gene tree/species tree conflict. This use of consensus analysis is inappropriate for two reasons (Mirkin et al., 1995): first, consensus methods cannot accommodate differing sets of terminal entities (Page, 1996), such as arises from gene trees exhibiting polymorphism or simply from gene trees with sequences sampled from different species; and second, consensus trees do not represent real biological events.

Rodrigo et al. (1993) have advocated a sequenceexcision procedure, wherein problem sequences are excised, the data sets tested for homogeneity, and the procedure repeated until the null hypothesis that two data sets represent character samples from the same phylogeny cannot be rejected. Excising sequences, however, may not be the best way to accommodate gene tree conflict (see bel ow).

Page (1994a), Mirkin et al. (1995), and Guigo et al. (1996) describe a method for inferring species trees from gene trees that avoids the problems discussed above. Under their method, the preferred species phylogeny is the one that minimizes the number of gene duplications plus gene losses necessary to fit each gene tree to the species tree. This method uses an optimization procedure that fits a gene tree to a species tree by assuming that the gene tree is actually a subtree of a larger tree chosen so as to minimize the number of gene duplications plus gene losses (either gene extinctions or 
simply failures to sample genes) necessary to make the original gene tree and species tree congruent. This optimization procedure was initially investigated by Goodman et al. (1979) and later formalized by Page (1994a) as "tree reconciliation." An example of tree reconciliation is shown in Fig. 2: gene tree $2 \mathrm{~A}$ can be fit to species tree $2 \mathrm{~B}$ by assuming that the gene tree is a subtree of the reconciled tree shown in 2C. Tree reconciliation is implemented in Page's (1993) program COMPONENT 2.0.

This approach shows great promise, especially because reconciled trees are hypotheses of real biological events, but it is overly restrictive because it assumes that all gene tree/species tree conflict is due to gene duplication. Thus, it is necessary to generalize the method to include the other possible sources of gene tree/species tree conflict, namely deep coalescence and lateral transfer. We call the generalized approach gene tree parsimony and define it as a method which finds the species tree that minimizes the weighted sum of deep coalescences, gene duplications plus losses, and lateral transfers necessary to fit each gene tree to the species tree. Gene tree parsimony has an undeniable logic: if a gene tree is different than the true species

A
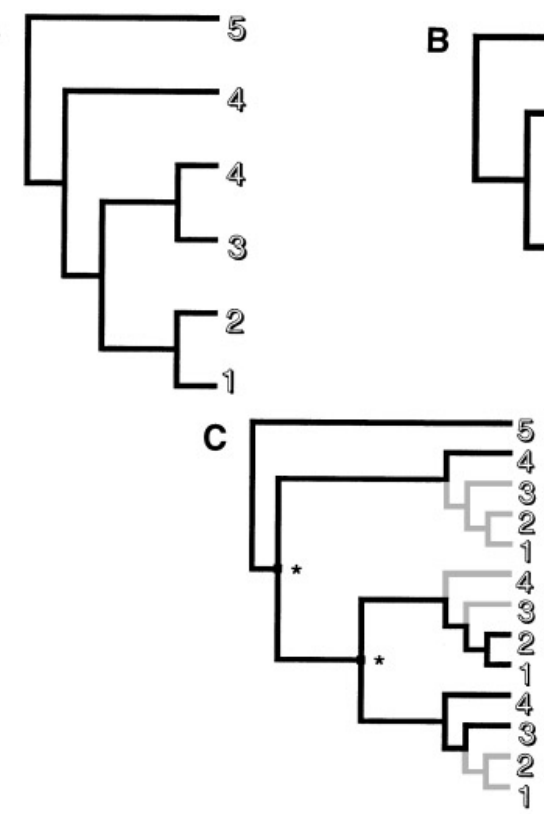

D

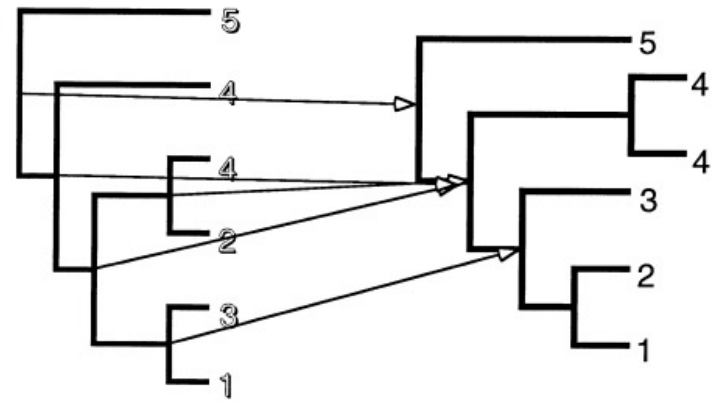

tree, it is due to some combination of deep coalescences, gene duplications, and lateral transfers. Therefore, it is biologically realistic to consider these as the fundamental events to minimize under a parsimony criterion for inferring species phylogeny. A practical feature of gene tree parsimony is that the individual gene trees need not be based on the same sets of species. Parsimony is not the only possible method for finding a species phylogeny based on reconstructing deep coalescences, gene duplications, and lateral transfers. If one is willing to assign probabilities to these events, then a maximum likelihood approach is also possible. Many papers have modeled the probabilities of deep coalescences under simple, stochastic models (e.g., Pamilo and Nei, 1988; Takahata, 1989; Wu, 1991).

To generalize gene tree parsimony to include deep coalescence and lateral transfer, it is first necessary to have optimization procedures comparable to tree reconciliation for these two types of conflict-producing events. F or deep coalescence, a simple optimization procedure can be used based on Page's (1994a) concept of generating maps between trees. First, the sequence names on the gene tree are replaced with the names of the species from which they were sampled. Then each cluster on the gene tree is mapped to the smallest cluster on the species tree that contains all the species in the gene

FIG. 2. Optimization methods for implementing gene tree parsimony. Tree $A$ is a gene tree for six sequences sampled from species $1-5$, whose relationships are shown in $B$. The sequence names have been replaced with the species' names and are shown in shadowed outline. Under the assumption that the observed gene tree/species tree conflict is due to gene duplication coupled with unsampled or extinct sequences, the gene tree can be fit to the species tree by postulating gene tree C, a new tree termed the "reconciled tree" (Page, 1994a). Tree $C$ represents the minimal number of duplications (asterisks) plus losses (gray branches) (2 duplications/4 losses) required to fit tree $A$ to tree $B$. Under the different assumption that the gene tree/species tree conflict is due to deep coalescence, a different procedure can be used to fit a gene tree to a species tree based on Page's (1994a) concept of mapping clades. Each cluster on the gene tree is mapped to the smallest cluster on the species tree that contains all the species from which the sequences were sampled. (In the case of a species with multiple or missing sequences, it is necessary to temporarily modify the species tree by repeating the species as many times as there are extra sequences or deleting the species altogether, respectively.) Any unmapped clades on the species tree represent deep coalescence events for the sequences sampled from the species contained in the clade. In D, a gene tree (on left) is mapped to a species tree, a fit that requires two deep coalescences because the sequences from species 1 and 2 and the two sequences from species 4 fail to coalesce within the ancestors of those species. It is also possible to weight each deep coalescence by a function of its depth, which is probably desirable because deeper deep coalescences are less likely than shallower deep coalescences. The simplest procedure is to simply weight each deep coalescence by the number of interior nodes removed it is from the ancestor of the species from which the sequences were sampled. In $D$, deep coalescence $1 / 2$ would be weighted 2 and deep coalescence $4 / 4$ would be weighted 1 for a total cost of 3 . 
tree cluster (Fig. 2D). The number of unmapped clusters on the species tree counts the minimum number of deep coalescences necessary to fit the gene tree to the species tree. In the case of a species with multiple or missing sequences, it is necessary to temporarily modify the species tree by repeating the species as many times as there are extra sequences or by deleting the species altogether, respectively. This optimization procedure gives a simple, unweighted count of the number of deep coal escences required to fit a gene tree to a species tree; it does not take into account the depth of each deep coalescence. In fact, some way to weight deep coalescences by a function of depth is desirable because deeper deep coalescences are less likely than shallower deep coalescences. The simplest method is a linear weighting scheme that weights each failed coalescence by its depth measured in interior nodes (see Fig. 2D).

Page $(1994 a, b)$ and Page and Charleston (manuscript) discuss ways to fit a gene tree to a species tree under the assumption that conflict is due to lateral transfer. Hybridization is probably rare in certain taxa, including snakes, but common in other taxa, especially plants. Because there is little evidence of hybridization in elapid snakes, we will assume in the remainder of this paper that all conflict between elapid gene and species trees is due to some combination of deep coalescence and gene duplication.

Genetree parsimony expands the phylogenetic analysis of species based on molecular sequences to two levels: first, gene trees are individually reconstructed from all loci under consideration, and second, the species phylogeny is inferred from the set of gene trees. This approach implements the concept (Doyle, 1992) that nucleotides are characters of gene trees, whereas gene trees are characters of species trees.

As mentioned above, the methods discussed in this paper make two assumptions with regard to gene trees: first, the terminal sequences of a gene tree have shared a single history representable by a binary tree, and second, this tree has been correctly inferred. The former assumption may in some cases be tenuous, especially for long sequences, because of the possibility of recombination. Recombination conjoins sets of nucleotides that have had different histories and results in sequences with composite histories, in which case it is illogical to represent the sequences' history with a single tree. In theory, historically linked units within genes with composite histories should be identifiable. The same methods (Huelsenbeck et al., 1996) used to test whether two genes share the same history might potentially be applied to this problem by testing all $n-$ 1 bipartitions of contiguous sites within a single gene of $\mathrm{n}$ aligned characters for homogeneity. A failure to reject the null hypothesis of homogeneity for all of the $n-1$ tests would suggest that no recombination had occurred.

\section{MATERIALS AND METHODS}

\section{Venom Protein Sequences}

All sequences were retrieved from the protein database SWISS-PROT using NCBI's Taxonomy Browser. We obtained 59 Type IA PLA 2 sequences for 23 species of elapids in 12 genera. Two Type IB sequences (Oxyuranus scutellatus, P00616; Pseudonaja textilis, P23028) served as outgroups. The SWISS-PROT accession numbers for the ingroup PLA $\mathrm{A}_{2}$ sequences are as follows: Ai pysurus laevis, P08872; Aspidel aps scutatus, P07037; Bungarus fasciatus, P00627-00629, P14411, P14615, P29601; B. multicinctus, P00606, P00617-00619, P17934; Enhydrina schistosa, P00610; Hemachatus haemachatus, P00595; Laticauda colubrina, P1011610117; L. Iaticaudata, P19000; L. semi fasciata, P0061100613; Maticora bivirgata, P24644; Naja atra, P00598; N. kaouthia, P00596-00597; N. melanoleuca, P0059900601; N. mossambica, P00602-00604; N. naja, P15445; N. nigricollis, P00605; N. oxiana, P25498; N. pallida, P14556; Notechis scutatus, P00607-00609, P08873, P20146; Oxyuranus scutellatus, P00614-00615; Pseudechis australis, P04056-04057, P20250-20257; P. porphyriacus, P20258-20259; Pseudonaja textilis, P2302623027, P30811.

Forty-two NXS sequences were retrieved for 27 species in 12 genera. Based on Tamiya's (1985) work with elapid NXSs, we used the sequences from Dendroaspis as outgroups (D. jamesoni, P01417; D. pol ylepis, P01416; D. viridis, P01418). The SWISS-PROT accession numbers for the ingroup NXS sequences are as follows: Acanthophis antarcticus, P01434; Aipysurus laevis, P19958-19960, P32879; Astrotia stokesii, P01438; Boulengerina annulata, P34075; B. christyi, P34076; Bungarus fasciatus, P10808; Enhydrina schistosa, P2549225493; Hemachatus haemachatus, P01425, P01433; Hydrophis cyanocinctus, P25494; H. Iapemoides, P01437; Laticauda colubrina, P10455-10457; L. crockeri, P10458, P25495-P25496; L. Iaticaudata, P1045910460; L. semifasciata, P01435; Naja atra, P01430; N. haje, P01420-01422, P01429, P25675; N. kaouthia, P14613; N. melanoleuca, P01424; N. mossambica, P01431-01432; N. nigricollis, P01423; N. oxiana, P01427; N. pallida, P01426; N. philippinensis, P01428; Pseudechis austral is, P25497.

Any signal sequences were removed prior to alignment. The sequences were aligned using GeneWorks, which resulted in 122 homologous sites for the $P L A_{2} S$ and 62 homologous sites for the NXSs (a copy of the alignments is available from the first author).

\section{GeneTreAnalysis}

All parsimony analyses were performed with PAUP* 4.0 (Swofford, 1997). We analyzed the data using the PROTPARS method of PHYLIP (Felsenstein, 1989), which assigns the distance between any pair of amino acids as the minimum number of nucleotide substitu- 
tions involving amino acid substitutions required to interconvert the amino acids. We feel that this method is superior to the unordered method (Fitch, 1971), which ignores the underlying genetic code. Only the subsets of sites that formed informative characters were used. Gaps were treated as additional states. In all analyses, 10 sequential heuristic searches were run using starting trees generated by random stepwise addition. Branch swapping was performed using the tree-bisection reconnection method. PAUP's " $3+1$ " option was employed as a shortcut for determining ancestral amino acids. To assess the quality of the data, we used three methods implemented in PAUP* 4.0: bootstrapping (Felsenstein, 1985), skewness (Hillis, 1991; Hillis and Huelsenbeck, 1992), and the permutation test (F aith and Cranston, 1991). Bootstrap proportions were based on 100 pseudosamples. Skewness was estimated from random samples of 10,000 trees. Permutation tests were based on 1000 replicates, the lengths of which were found by heuristic searches using stepwise addition only (no branch swapping).

\section{Species TreeAnalysis}

To implement gene tree parsimony, we used test version 0.75 of GeneTree (Page and Charleston, 1997), a program written by Rod Page for Mad ntosh computers that searches for the shortest species tree(s) under the optimality criterion of minimizing the number of deep coal escences or gene duplications plus unsampled sequences (currently, the program does not consider lateral transfer). At present, GeneTree can only minimize the number of deep coalescences or gene duplications plus losses during a run but not both simultaneously. This is equivalent to performing a run where one type of event is given a weight of 1 , while the other is given a weight of 0 . Mixed analyses are probably more realistic, but this involves the complex issue of how deep coalescence and duplication events should be weighted relative to each other. When the criterion of minimizing deep coalescences is in effect, GeneTree calculates the cost of a species tree by weighting each deep coal escence by its depth as described under I nferring Species Trees from GeneTrees (see Fig. 2). When no sequences for a particular gene have been sampled from a species, GeneTree treats this as missing data; that is, the missing sequences are not counted as losses under the duplication criterion. This has the desirable effect of eliminating spurious clades formed by the shared absence of sequences for a gene.

Prior to all analyses, the outgroup sequences were removed from the gene trees. Heuristic searches were run using starting trees generated by random stepwise addition. Branch swapping was done with the ALT option, which alternates between nearest-neighbor interchanges and subtree pruning and regrafting. This method is the most effective (Page and Charleston,
1997) of the branch-swapping options available in GeneTree.

J ust as with any phylogenetic method, some way of assessing the quality of the data (and, hence, of the results) is desirable. Perhaps the simplest method would be a randomization procedure, wherein the sequence names are randomly permuted at the tips of each gene tree, followed by inference of the shortest species tree from the permuted gene trees using gene tree parsimony. This is repeated many times to build a distribution of species tree lengths under the null model of no phylogenetic structure. The observed species tree length is then compared to the null distribution. Another method would be to simply perform bootstrapping using the gene trees as characters (but this would not be informative with low numbers of gene trees, as with the present study). At present, GeneTree does not implement any methods for testing the similarity among gene trees. We used the following method: first, GeneTree was used to find the shortest species trees from each gene tree analyzed separately by minimizing deep coalescences; second, any unshared species were pruned from the species trees; third, we calculated the similarity of the pruned PLA 2 and NXS species trees by counting the number of shared clades; and fourth, we tested the null hypothesis that the two species trees may have been sampled randomly using the asymptotic equation of Hendy et al. (1988).

\section{RESULTS}

\section{GeneTrees}

From the PLA $A_{2}$ sequences, 30 shortest trees of 1268 steps were found (Fig. 3). Both the skewness $(\mathrm{gl}=-0.34)$ and the PTP tests $(P<0.001)$ indicate that the $\mathrm{PLA}_{2}$ sequences have strong phylogenetic structure when treated under the PROTPARS method.

From the NXS sequences, 108 shortest trees of 278 steps were found (Fig. 4). Both the skewness $(\mathrm{gl}=-0.45)$ and the PTP tests $(\mathrm{P}<0.001)$ indicate that the NXS sequences have strong phylogenetic structure when treated under the PROTPARS method.

For the species tree analyses, we arbitrarily chose the first tree from each of the two sets of shortest gene trees rather than use the consensus trees for the simple reason that GeneTree accepts only fully resolved trees. The arrows in Figs. 3 and 4 show the particular resolution used for each protein.

\section{Species Trees}

Under the criterion of minimizing duplications plus losses, GeneTree found >99 shortest species trees (currently, the program can only store 99 trees) (Fig. 5) from the PLA $A_{2}$ and NXS trees (Figs. 3 and 4 ) with a cost 


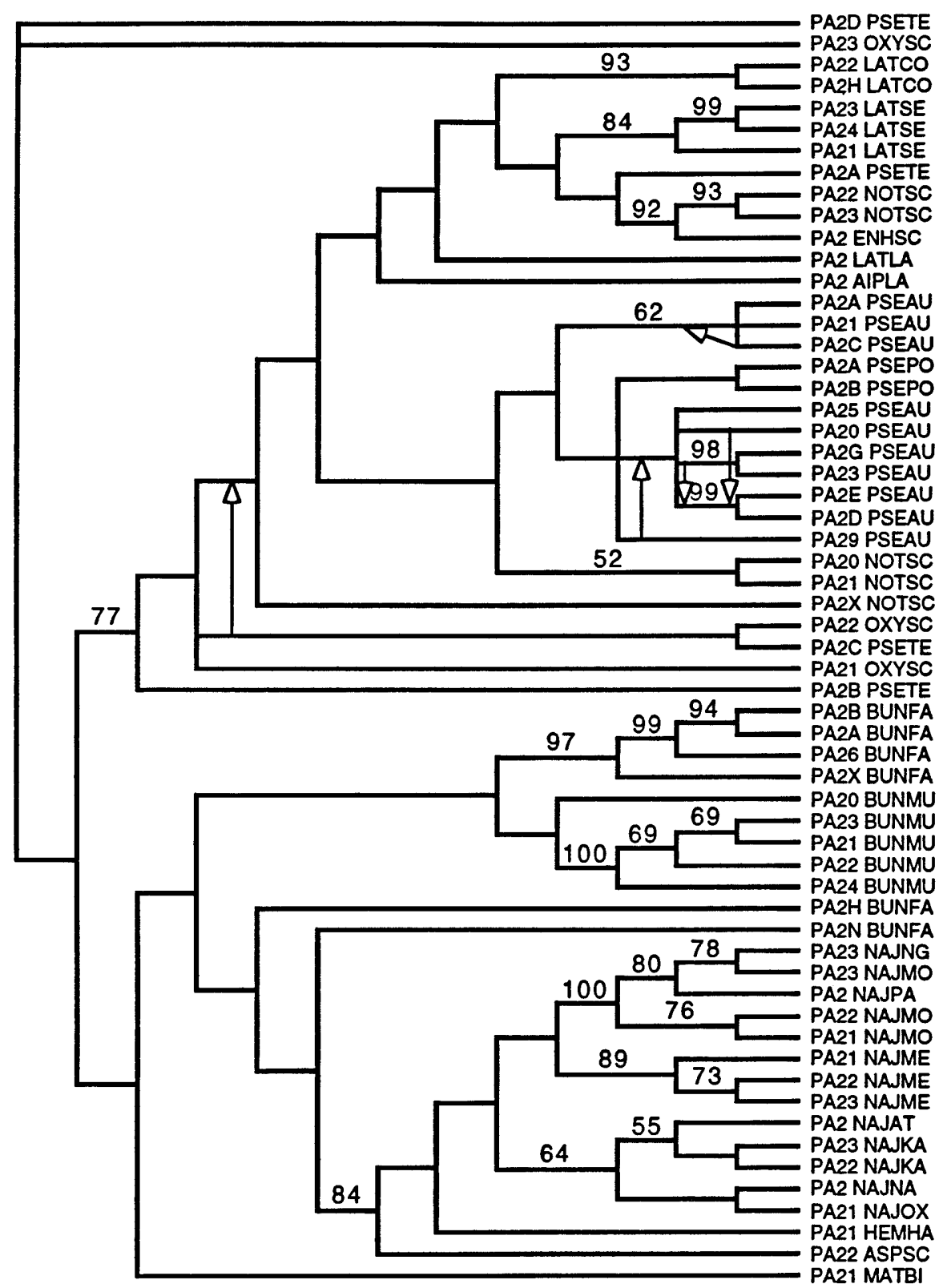

FIG. 3. The strict consensus tree (SCT) of the 30 shortest trees ( 1268 steps) resulting from a PROTPARS parsimony analysis of 59 elapid $\mathrm{PLA}_{2}$ sequences. The numbers al ong the internodes are the bootstrap portions that were greater than $50 \%$. The arrows indicate the particular resolution that was used for the GeneTree analyses (a branch is dragged onto the branch indicated by the arrow). Abbreviations: ACAAN, Acanthophis antarcticus; AIPLA, Aipysurus laevis; ASPSC, Aspidelaps scutatus; ASTST, Astrotia stokesii, BOUAN, Boulengerina annulata; BOUCH, B. christyi; BUNFA, Bungarus fasciatus; BUNMU, B. multicinctus; DENJ A, Dendroaspis jamesonii; DENPO, D. polylepis; DE NVI, D. viridis; ENHSC, Enhydrina schistosa; HEMHA, Hemachatus haemachatus; HYDCY, Hydrophis cyanocinctus; HYDLA. H. Iapemoides; LATCO, Laticauda colubrina; LATCR, L. crockeri; LATLA, L. Iaticaudata; LATSE, L. semifasciata; MATBI, Maticora bi virgata; NAJ AT, Naja atra; NAJ HA/NAJ HH, N. haje; NAJ KA, N. kaouthia; NAJ ME, N. melanoleuca; NAJ MO, N. mossambica; NAJ NA, N. naja; NAJ NG, N. nigricollis; NAJ OX, N. oxiana; NAJ PA, N. pallida; NAJ PH, N. philippinensis; NOTSC, Notechis scutalus; OXYSC, Oxyuranus scutellatus; PSEAU, Pseudechis australis; PSEPO, P. porphyriacus; PSETE, Pseudonaja textilis.

of 122 (deep coalescence cost ranged from 58-62). Under the criterion of minimizing deep coalescences, GeneTree found $>99$ shortest trees (Fig. 6) with a cost of 54 (duplication cost 131-135).

When the PLA $A_{2}$ and NXS trees are analyzed separately by GeneTree under the criterion of minimizing deep coalescences, the following results are obtained: the four shortest species trees (Fig. 7) based on the $\mathrm{PLA}_{2}$ tree have a length of 25 (duplication cost 68-71); the six shortest species trees (Fig. 8) based on the NXS tree have a length of 11 (duplication cost 23-26). Using the tree-comparison procedure described above under 


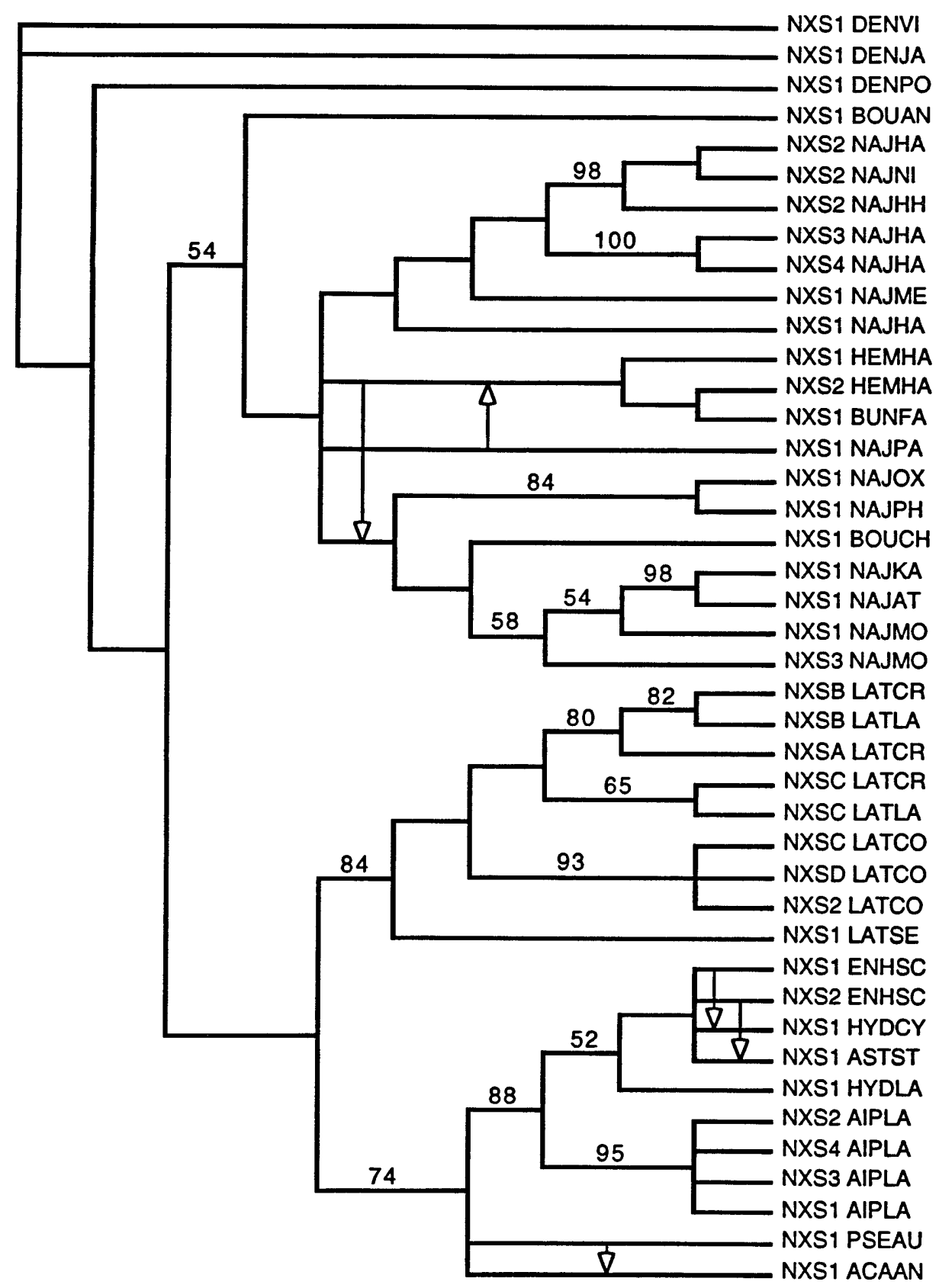

FIG. 4. The SCT of the 108 shortest trees ( 278 steps) resulting from a PROTPARS parsimony analysis of $42 \mathrm{NXS}$ sequences. The numbers along the internodes are the bootstrap proportions that were greater than $50 \%$. The arrows indicate the particular resolution that was used for the GeneTree analyses. See Fig. 3 for abbreviations.

Materials and Methods, the similarity among all 24 pairs of PLA $A_{2}$ and NXS species trees is three shared clades, which is highly significant $(P \sim 0.0003)$.

With regard to phylogenetic clustering, specific results are discussed in the following section.

\section{DISCUSSION}

In this paper, we have argued that the combined data, matrix representation, consensus, and sequence- excision methods for inferring species phylogenies from genes with conflicting histories are inappropriate. Instead, we have presented a method we call gene tree parsimony that operates by finding the species tree that minimizes a weighted sum of the different kinds of conflict-producing events necessary to fit each gene tree to the species tree. The program we used to implement gene tree parsimony, GeneTree (Page and Charleston, 1997), only allows one to minimize either deep coalescence or gene duplication, but not both simultaneously. 


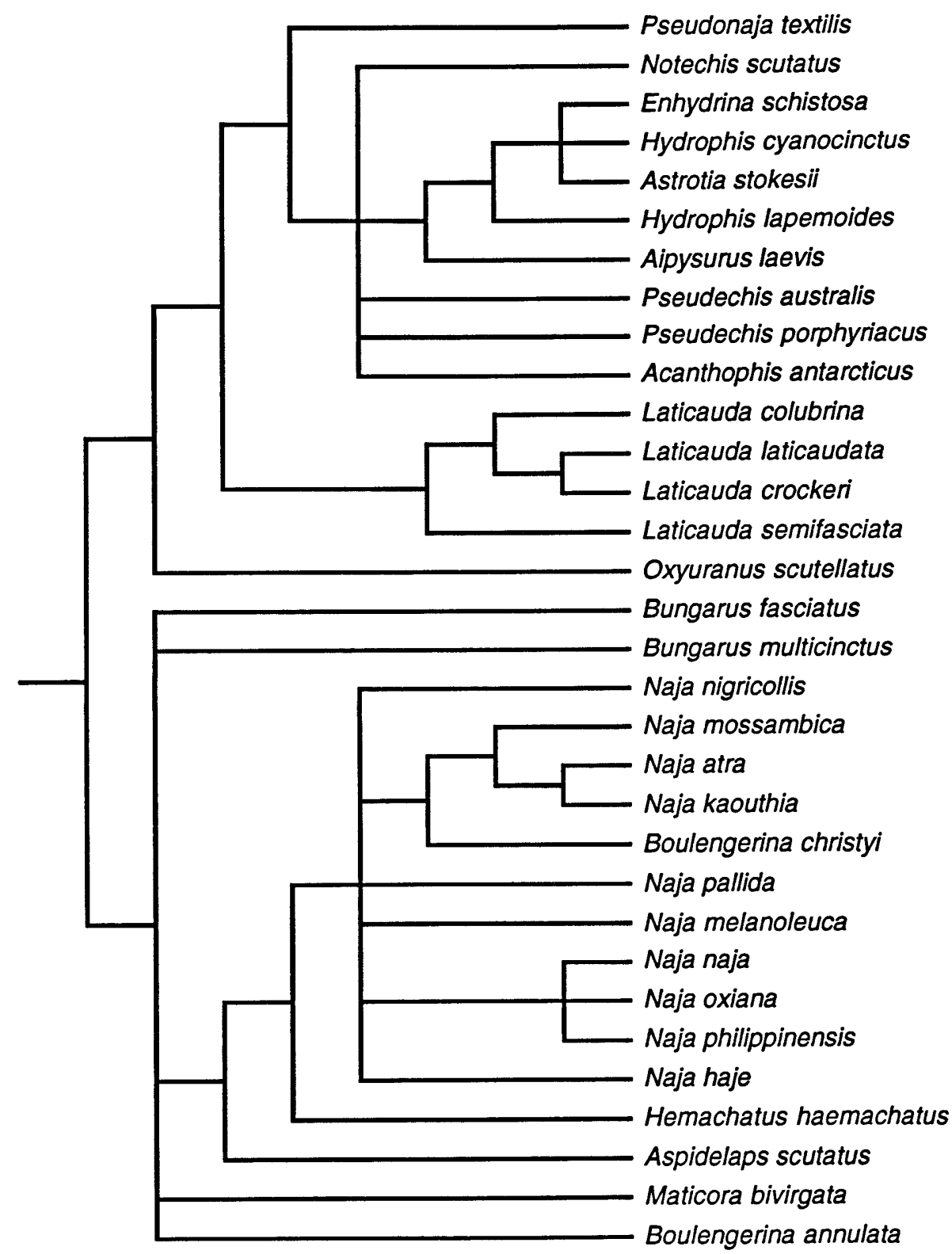

FIG. 5. The SCT of the 99 shortest species trees resulting from analysis of the PLA $A_{2}$ and NXS gene trees using gene tree parsimony implemented with GeneTree where the number of duplications plus losses (cost $=122$ ) was minimized.

Mixed analyses may be more realistic, but this will involve decisions on how to weight the two kinds of events relative to each other. Additionally, future work on optimization algorithms will be required before lateral transfer can be incorporated.

In the following discussion, we describe our findings with regard to elapid relationships as inferred from the $\mathrm{PLA}_{2}$ and NXS genes using gene tree parsimony and compare them to the results of previous studies, both morphological and molecular. In doing so, we emphasize areas of corroboration, which is probably the best arbiter of the accuracy of phylogenetic hypotheses, and hence the methods used to derive them (Penny et al., 1982; Miyamoto and Cracraft, 1991; Slowinski, 1993).
The elapids examined in our study were found to fall into two sister groups (Figs. 5 and 6), one containing the marine (Aipysurus, Astrotia, Enhydrina, Hydrophis, and Laticauda) and terrestrial Australian (Acanthophis, Notechis, Oxyuranus, Pseudechis, and Pseudonaja) species, and the other containing the African and Asian species (Aspidelaps, Boulengerina, Bungarus, Hemachatus, Maticora, and Naja). This result is simiIar to the results of earlier phylogenetic studies of $\mathrm{PLA}_{2} \mathrm{~S}$ (Dufton and Hider, 1983; Tamiya, 1985; Davidson and Dennis, 1990; Kostetsky et al., 1991) and corresponds largely to McDowell's (1970) basic division of elapids into palatine draggers (all Australasian terrestrial [except Parapistocalamus] and marine [ex- 


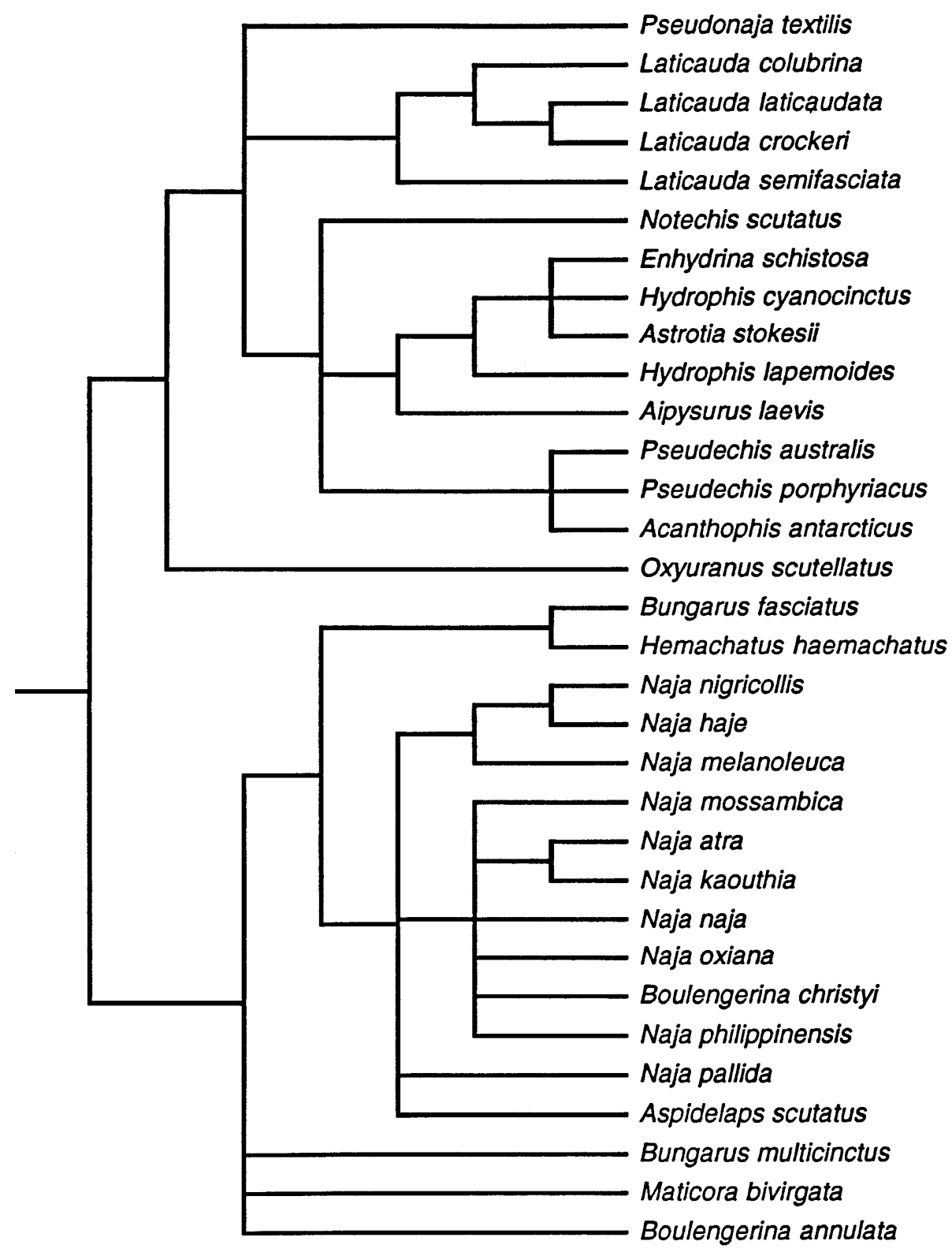

FIG. 6. The SCT of the 99 shortest species trees resulting from analysis of the PLA $A_{2}$ and NXS gene trees using gene tree parsimony implemented with GeneTree where deep coalescences (cost $=54$ ) were minimized.

cept Laticauda] elapids) and palatine erectors (all terrestrial African, Asian, and American elapids, Laticauda, and Parapistocalamus), respectively. A major difference between our study and McDowell's is our association of Laticauda with the terrestrial Australian and marine elapids. A phylogenetic association be tween Australian terrestrial elapids with both laticaudine and hydrophiinesea snakes has been supported by other molecular studies (Minton and da Costa, 1975; Cadle and Gorman, 1981; Mao et al., 1983; Schwaner et al., 1985). Several studies that have not included Australian terrestrial genera, both molecular (Mao et al., 1977, 1978; Guo et al., 1987; Murphy, 1988) and morphological (McCarthy, 1986), have united laticaudines and hydrophiines to the exclusion of African, American, and Asian forms. Thus, contrary to McDowell's (1967, 1969, 1972) placement of laticaudines with Calliophis, Maticora, Parapistocalamus, and New World coral snakes (Micruroides and Micrurus), the balance of evidence supports an association of the laticaudines with the hydrophiine sea snakes and Australian terrestrial species.

Our results (Figs. 5 and 6) indicate that the sea snakes are diphyletic, with the laticaudines and hydrophiines having separate origins. The hydrophiine sea snakes (Enhydrina, Astrotia, Hydrophis, and Aipysu- 
rus) clustered with the Australian Notechis, Pseudechis, and Acanthophis, while Laticauda is separated from this group by Pseudonaja (Fig. 5). This result is corroborated by previous studies. Shine (1985a) has pointed out that two morphological features, viviparity and undivided subcaudals, are shared between hydrophiines and the following Australian genera (recognized by Hutchinson, 1990): Acanthophis (subcaudals partially divided), Austrelaps, Denisonia, Drysdalia, Echiopsis, Elapognathus, Hemiaspis, Hoplocephalus, Notechis, Rhinoplocephalus, Suta, and Tropidechis. The remaining Australian elapids and Laticauda are oviparous (except for Pseudechis porphyriacus) and possess divided subcaudals. (Several authors haveerroneously reported Laticauda colubrina to be viviparous [Shine, 1985b].) Viviparity and undivided subcaudals are derived characters within elapids and support an association between hydrophiines and the aforementioned terrestrial Australian genera (except for Pseudechis, which possess divided subcaudal scales) to the exclusion of the laticaudines. Further support for an association between hydrophiines and viviparous Australian elapids comes from Schwaner et al. (1985) and

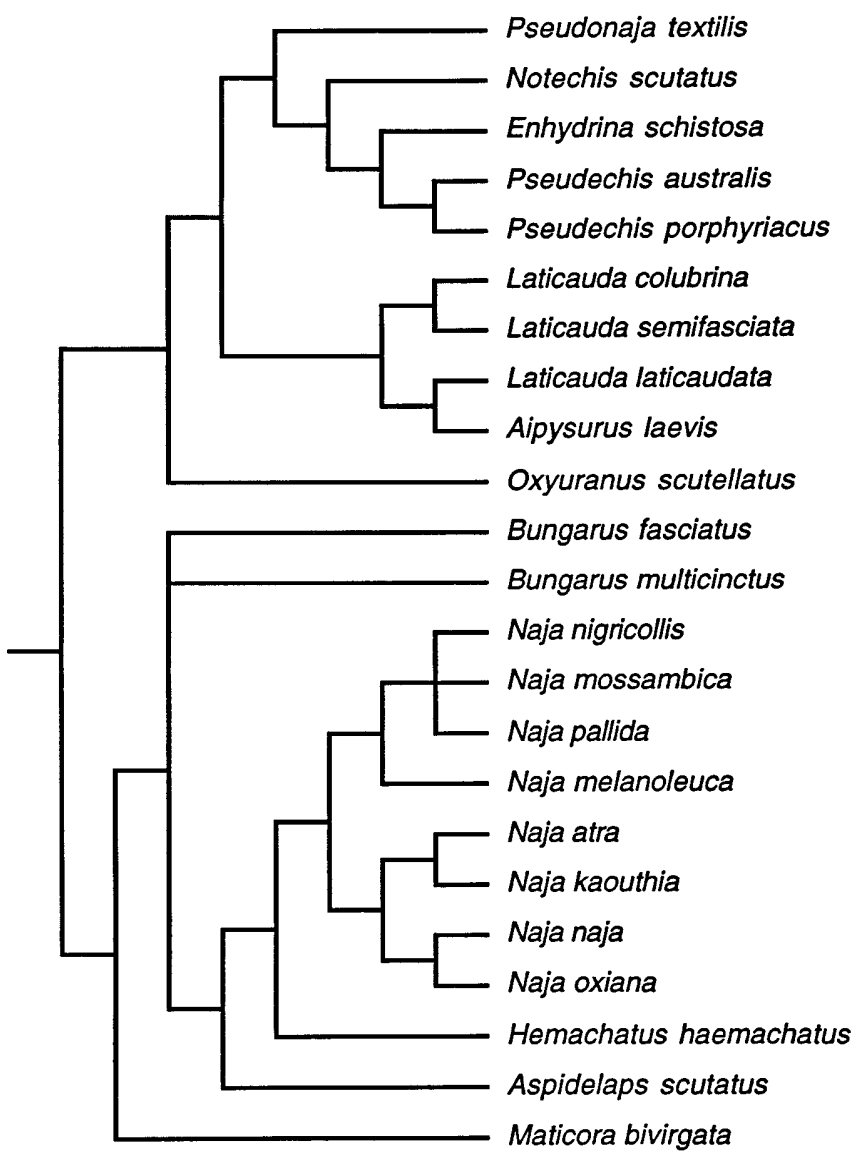

FIG. 7. The SCT of the four species trees generated from the $\mathrm{PLA}_{2} \mathrm{~S}$ alone (Fig. 3) using GeneTree and minimizing deep coalescences (cost $=25)$.

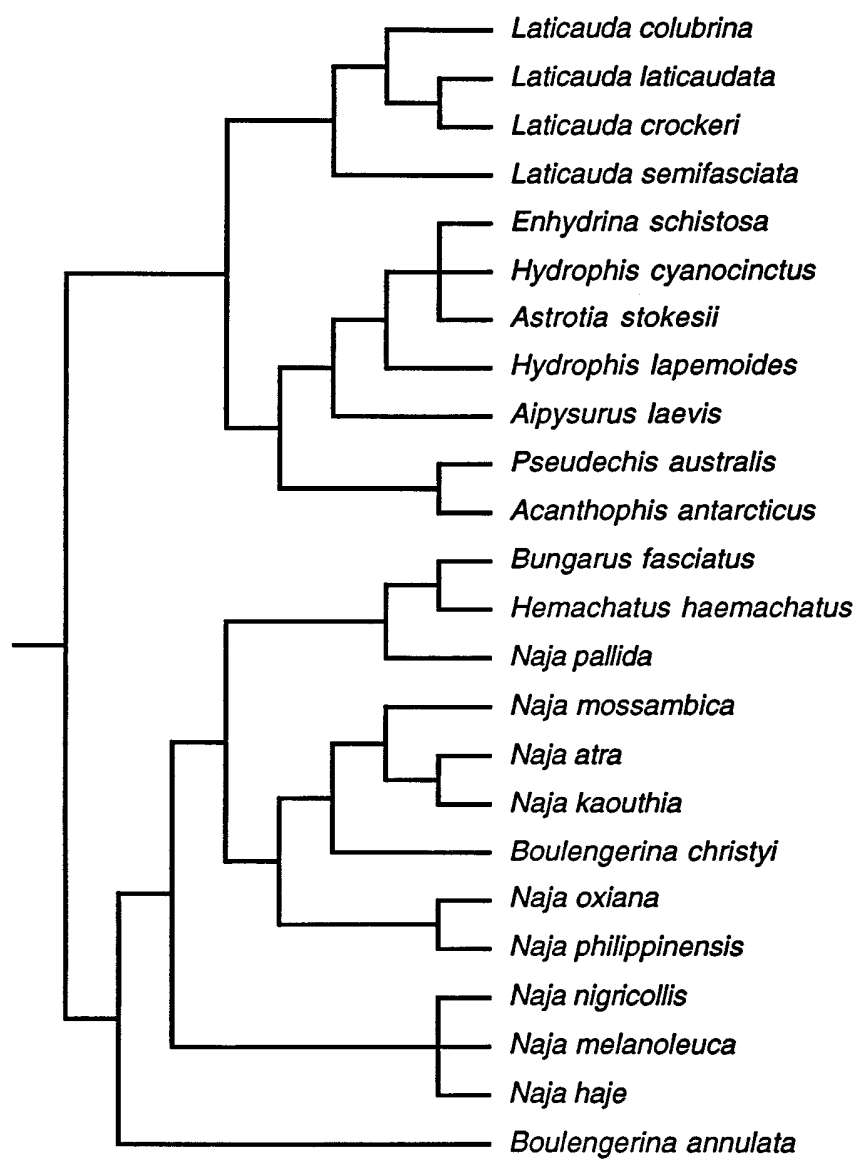

FIG. 8. The SCT of the six species trees generated from the NXSs alone (Fig. 4) using GeneTree and minimizing deep coalescences (cost $=11$ )

Gopalakrishnakone and Kochva (1990). Schwaner et al . (1985) examined transferrin immunological distances among a variety of Australian elapids and sea snakes, as well as several African and Asian forms. They found that laticaudines and hydrophiines were close to the Australian lineages, but that laticaudines and hydrophiines had arisen separately and that hydrophiines were especially close to Notechis. Gopalakrishnakone and Kochva (1990) found similarities in venom gland morphol ogy between hydrophiines and the "Notechis group" of Australian terrestrial elapids and suggested an evolutionary link. Clearly, hydrophiines have arisen within a clade that includes the Australian viviparous species, whereas Laticauda has arisen independently from within a clade of Australian oviparous species.

In our study, we examined several African and Asian genera, but none of theAmerican genera (Micrurus and Micruroides), for which complete venom protein sequences are not yet available. However, there is some support for the African, American, and Asian forms being collectively monophyletic. Murphy (1988), in a phylogenetic study of six elapid genera, found an association of Micrurus, Micruroides and Naja to the 
exclusion of Laticauda, Pelamis, and Emydocephalus. We must point out that the relationships of theAfrican genus Dendroaspis are problematical. Tamiya (1985) found that the NXSs of this genus were the most divergent of any examined for elapids, which led us to treat them as the outgroup sequences in our gene tree analyses. Further work is needed to clarify the position of Dendroaspis.

Our study (Figs. 5 and 6) suggests that both the African (Naja nigricollis, N. haje, N. melanoleuca, N. mossambica, and N. pallida) and Asian (N. atra, N. kaouthia, N. naja, N. oxiana, and N. philippinensis) Naja may be nonmonophyletic. This may be true of the African Naja, but is probably not true for the Asian Naja, for which morphological synapomorphies are known (Szyndlar and Rage, 1990). If we consider the $\mathrm{PLA}_{2} \mathrm{~S}$ alone (Fig. 7), the monophyly of Asian Naja is corroborated.

The foregoing discussion has important implications for elapid classification. In his influential classification, Boulenger (1896) divided theE lapidae into the subfamilies Hydrophiinae and Elapinae. He placed both laticaudine and hydrophiine sea snakes into the Hydrophiinae, and all other elapids into the Elapinae. In his monograph on sea snakes, Smith (1926) also included laticaudines and hydrophiines together, but at the elevated rank of family (Hydrophiidae). Boulenger's (1896) subfamilial scheme was adopted in Underwood's (1967) classification, although he expressed some skepticism regarding a close relationship between laticaudines and hydrophiines. McDowell's (1967, 1969, 1970, 1972) extensive morphological work on elapids led him to conclude that hydrophiines were related to terrestrial Australasian elapids, but that laticaudines were actually related to elapines. The classification of Smith et al. (1977) reflected McDowell's conclusions: Laticauda was included in the Elapidae with the African, American, and Asian species, while hydrophiines and terrestrial Australasian elapids were combined in the Hydrophiidae. Burger and Natsuno (1974) chose a different classification, placing laticaudines in their own family, the Laticaudidae, to reflect McDowell's $(1967,1969,1970,1972)$ contention of a separate origin for laticaudines.

Although it is clear that hydrophiines are indeed related to the terrestrial Australasian elapids, the laticaudines are not allied to the Asian, African, and American forms, but instead to the hydrophiines and terrestrial Australasian forms. Therefore, we advocate the following subfamilial classification of elapids:

Elapinae Boie 1827, including all terrestrial Asian, African, and American genera;

Hydrophiinae Fitzinger 1843, including all marine genera and the terrestrial Australo-Papuan and Melanesian genera.
This scheme is similar to Smith et al .'s (1977) classification, which is based on the work of McDowell, except that our classification includes Laticauda in the Hydrophiinae. In their classification, Smith et al. subdivided their Hydrophiidae into the subfamilies Hydrophiinae for the hydrophiine sea snakes and Oxyuraninae for the Australasian taxa. Because our study shows that Oxyuraninae is paraphyletic relative to sea snakes, the taxon should be abandoned. Partition of Hydrophiinae sensu novo must await further resolution of therelationships of these elapids.

In our study, the elapines examined (Aspidelaps, Boulengerina, Bungarus, Hemachatus, Maticora, and $\mathrm{Naja}$ ) cluster ed together, but as pointed out earlier, the position of theAfrican Dendroaspis is problematical.

Our phylogeny has important implications for the historical biogeography of hydrophiines (sensu novo). Based on immunological distances together with a calibration of 1.6 substitutions per million years, Schwaner et al. (1985) dated the split between elapines and hydrophiines at early Miocene (20 MYA). Based on this, Cadle (1987) argued for a relatively recent origin for Australian elapids, suggesting that they originated via Miocene dispersal from southeast Asia. However, two lines of evidence argue against the Miocenedispersal-from-Asia hypothesis for the origin of hydrophiines. First, Miocene el apid fossils representing modern genera have been reported by Holman (1979; Micrurus) and Rage (1987; Naja). Thus, some of the terminal splits among elapids had al ready occurred by the Miocene. Considering that the split between hydrophiines and elapines represents the basal split within elapids, not a terminal split, then clearly the division between elapines and hydrophiines predates the Miocene and probably considerably so, an idea that has been suggested by other authors (e.g., Cogger and Heatwole, 1981; Cogger, 1984). We ascribe Schwaner et al.'s results to a rate slow-down in the evolution of elapid plasma transferrins. Second, if hydrophiines originated from Asian elapids, then hydrophiines would be expected to have an Asian sister group. But, in fact, the sister group of hydrophiines is the African, American, and Asian species.

The fact that hydrophiines predate the Miocene is significant because it was only in the late Miocene that Australia was close enough to Asia to allow migration from that source (Galloway and Kemp, 1981). This makes it likely that hydrophiines represent a Gondwanian group that has remained in situ in the Australian region since the break-up of Gondwanaland.

\section{ACKN O WLEDG MENTS}

We are greatly indebted to R. Page for writing GeneTree, for allowing us access to test versions, and for his constant advice on the program. We thank D. Swofford for allowing us to use test versions of PAUP* 4.0. We thank J. Boundy, B. Crother, R. Page, and M. White for commenting on the manuscript. 


\section{REFERENCES}

Avise, J. C., Shapiro, J. F., Daniel, S. W., Aquadro, C. F., and Lansman, R. A. (1983). Mitochondrial DNA differentiation during the speciation process in Peromyscus. Mol. Biol. Evol. 1: 38-56.

Boulenger, G. A. (1896). Catalogue of snakes of the British Museum (Natural History), Vol. III, Containing the Colubridae (OpisthogIyphae and Proteroglyphae), Amblycephalidae, and Viperidae, London.

Bull, J . J ., Huelsenbeck, J . P., Cunningham, C. W., Swofford, D. L., and Waddell, P. J. (1993). Partitioning and combining data in phylogenetic analysis. Syst. Biol . 42: 384-397.

Burger, W. L., and Natsuno, T. (1974). A new genus for the Arafura smooth sea snake and redefinitions of other sea snake genera. Snake 6: 61-75.

Cadle, J . E. (1987). Geographic distribution: Problems in phylogeny and zoogeography. In "Snakes: Ecology and Evolutionary Biology" (R. A. Seigel, J. T. Collins, and S. S. Novak, Eds.), pp. 77-105, Macmillan, New York.

Cadle, J. E., and Gorman, G. C. (1981). Albumin immunological evidence and the relationships of sea snakes. J. Herpetol. 15: 329-334.

Cadle, J . E., and Sarich, V. M. (1981). An immunological assessment of the phylogenetic position of New World coral snakes. J . Zool. London 195: 157-167.

Cogger, H. G. (1984). Reptiles in the Australian arid zone. In "Arid Australia" (H. G. Cogger and E. E. Cameron, Eds.), pp. 235-252, Australian Museum, Sydney.

Cogger, H. G., and Heatwole, H. (1981). The Australian reptiles: Origins, biogeography, distribution patterns and island evolution. Monogr. Biol. 41: 1331-1374.

Davidson, F. F., and Dennis, E. A. (1990). Evolutionary relationships and implications for the regulation of phospholipase $A_{2}$ from snake venom to human secreted forms. J. Mol. Evol. 31: 228-238.

De Haas, G. H., and Van Deenen, L. L. M. (1961). Synthetic mixed-acid kephalins; hydrolysis by 'phospholipase $A^{\prime}$ ' and some properties of their sodium salts. Biochem. J . 81: 34-35.

De Queiroz, A. (1993). For consensus (sometimes). Syst. Biol. 42: 368-372.

De Queiroz, A., Donoghue, M. J ., and Kim, J . (1995). Separate versus combined analysis of phylogenetic evidence. Annu. Rev. E col. Syst. 26: 657-681.

Doyle, J . J . (1992). Gene trees and species trees: Molecular systematics as one-character taxonomy. Syst. Bot. 17: 144-163.

Dufton, M. J ., and Hider, R. C. (1983). Classification of phospholipases $A$ according to sequence: Evolutionary and pharmacological considerations. J . Biochem. 137: 545-551.

Faith, D. P., and Cranston, P. S. (1991). Could a cladogram this short have arisen by chance alone? On permutation tests for cladistic structure. Cladistics 7: 1-28.

Felsenstein, J . (1985). Confidence limits on phylogenies: An approach using the bootstrap. Evolution 39: 783-791.

Felsenstein, J . (1989). PHYLIP_Phylogenetic Inference Package, Version 3.2. Cladistics 5: 164-166.

Fitch, W. M. (1971). Toward defining the course of evolution: Minimal change for a specific tree topology. Syst. Zool. 20: 406-416.

Galloway, R. W., and Kemp, E. M. (1981). Late Cainozoic environments in Australia. In "E cological Biogeography of Australia" (A. Keast, Ed.), pp. 51-80, Dr W. J unk, The Hague.

Golay, P., Smith, H. M., Broadley, D. G., Dixon, J . R., McCarthy, C., Rage, J.-C., Schatti, B., and Toriba, M. (1993). "Endoglyphs and Other Major Venomous Snakes of the World. A Checklist," Azemiops, Switzerland.

Goodman, M., Czelusniak, J ., Moore, G. W., Romero-Herrera, A. E., and Matsuda, G. (1979). Fitting the gene lineage into its species lineage, a parsimony strategy illustrated by cladograms constructed from gl obin sequences. Syst. Zool . 28: 132-163.

Gopalakrishnakone, P., and Kochva, E. (1990). Venom glands and some associated muscles in sea snakes. J . Morphol. 205: 85-96.

Guigo, R., Muchnik, I., and Smith, T. F. (1996). Reconstruction of ancient molecular phylogeny. Mol. Phylogenet. Evol. 6: 189-213.

Guo, Y.-W., Mao, S.-H., and Yin, F.-Y. (1987). Comparison of cobra plasma albumins with those of banded krait and sea snake. Comp. Biochem. Physiol. 87B: 559-566.

Heinrikson, R. L., Krueger, E. T., and Keim, P. S. (1977). Amino acid sequences of phospholipase $A_{2}-\alpha$ from the venom of Crotalus adamanteus. J . Biol. Chem. 252: 4913-4921.

Hendy, M. D., Steel, M. A., Penny, D., and Henderson, I. M. (1988). Families of trees and consensus. In "Classification and Related Methods of Analysis" (H. H. Bock, Ed.), pp 355-362, Elsevier Science, Amsterdam.

Hillis, D. M. (1991). Discriminating between phylogenetic signal and random noise in DNA sequences. In "PhylogeneticAnalysis of DNA Sequences" (M. M. Miyamoto and J . Cracraft, Eds.), pp. 278-294, Oxford Univ. Press, New York.

Hillis, D. M., and Huelsenbeck, J. P. (1992). Signal, noise, and reliability in molecular phylogenetic analyses. J. Heredity 83: 189-195.

Holman, J . A. (1979). A review of North American Tertiary snakes. Pub. Mus. Mich. StateUniv. Paleontol. Ser. 11: 323-335.

Huelsenbeck, J. P., Bull, J. J ., and Cunningham, C. W. (1996). Combining data in phylogenetic analysis. TREE 11: 152-158.

Hutchinson, M. N. (1990). The generic classification of theAustralian terrestrial elapid snakes. Mem. Queensland Mus. 29: 397-405.

Karlsson, E. (1979). Chemistry of protein toxins in snake venoms. In "Snake Venoms" (C.-Y. Lee, Ed.), Vol. 52, pp. 159-212, Handbook of Experimental Pharmacology, Springer-Verlag, Berlin.

Kluge, A. G. (1989). A concern for evidence and a phylogenetic hypothesis of relationships among Epicrates (Boidae, Serpentes). Syst. Zool. 38: 7-25.

Kostetsky, P. V., Arkhipova, S. F., and Vladimirova, R. R. (1991). Conservative and variable regions of homologous snake phospholipases $A_{2}$ sequences: Prediction of the taxon specific peptides structure. J . Prot. Chem. 10: 593-601.

Mao, S.-H., Chen, B.-Y., and Chang, H.-M. (1977). The evolutionary relationships of sea snakes suggested by immunological crossreactivity of transferrins. Comp. Biochem. Physiol. A 57: 403-406.

Mao, S.-H., Chen, B.-Y., Yin, F.-Y., and Guo, Y.-W. (1983). I mmunotaxonomic relationships of sea snakes to terrestrial elapids. Comp. Biochem. Physiol. A 74: 869-872.

Mao, S.-H., Dessauer, H. C., and Chen, B.-Y. (1978). Fingerprint correspondence of hemogl obins and the relationships of sea snakes. Comp. Biochem. Physiol. B 59: 353-361.

McCarthy, C. J . (1985). Monophyly of the elapid snakes (Serpentes: Elapidae). An assessment of the evidence. Zool. J . Linn. Soc. 83: 79-93.

McCarthy, C. J . (1986). Relationships of the laticaudine sea snakes (Serpentes: Elapidae: Laticaudinae). Bull. British Mus. Nat. Hist. (Zool.) 50: 127-161.

McDowell, S. B. (1967). Aspidomorphus, a genus of New Guinea snakes of the family Elapidae, with notes on related genera. J . Zool. London 151: 497-543.

McDowell, S. B. (1968). Affinities of the snakes usually called Elaps lacteus and E. dorsalis. Zool. J . Linn. Soc. 47: 561-578.

McDowell, S. B. (1969). Toxicocalamus, a New Guinea genus of snakes of the family Elapidae. J. Zool. London 159: 443-511.

McDowell, S. B. (1970). On the status and relationships of the Solomon I sland elapid snakes. J . Zool. London 161: 145-190. 
McDowell, S. B. (1972). The genera of sea-snakes of the Hydrophis group (Serpentes: Elapidae). Trans. Zool. Soc. London 32: 189-247.

Minton, S. A., and Da Costa, M. S. (1975). Serological relationships of sea snakes and their evolutionary implications. In "The Biology of Sea Snakes" (W. Dunson, Ed.), pp. 33-55, University Park Press, Baltimore.

Mirkin, B., Muchnik, I., and Smith, T. F. (1995). A biologically consistent model for comparing molecular phylogenies. J . Comp. Biol. 2: 493-507.

Miyamoto, M. M., and Cracraft, J . (1991). Phylogenetic inference, DNA sequence analysis, and the future of molecular systematics. In "PhylogeneticAnalysis of DNA Sequences" (M. M. Miyamoto and J . Cracraft, Eds.), pp. 3-17, Oxford Univ. Press, New York.

Miyamoto, M. M., and Fitch, W. M. (1995). Testing species phylogenies and phylogenetic methods with congruence. Syst. Biol. 44: 64-76.

Murphy, R. W. (1988). The problematic phylogenetic analysis of interlocus heteropolymer isozyme characters: a case study from sea snakes and cobras. Canadian J . Zool . 66: 2628-2633.

Page, R. D. M. (1993). COMPONENT, version 2.0. The Natural History Museum, London.

Page, R. D. M. (1994a). Maps between trees and cladistic analysis of historical associations among genes, organisms, and areas. Syst. Biol. 43: 58-77.

Page, R. D. M. (1994b). Parallel phylogenies: reconstructing the history of host-parasite assemblages. Cladistics 10: 155-173.

Page, R. D. M. (1996). On consensus, confidence, and "total evidence." Cladistics 12: 83-92.

Page, R. D. M., and Charleston, M. A. (1997). From gene to organismal phylogeny: Reconciled trees and the gene tree/species tree problem. Mol. Phylogenet. Evol. 7: 231-240.

Page, R. D. M., and Charleston, M. A. Reconciled trees and incongruent gene and species trees. In "Mathematical Hierarchies in Biology," (B. Mirkin, F. R. McMorris, F. S. Roberts, and A. Rzhetsky, Eds.), Vol. 21, American Mathematical Society.

Pamilo, P., and Nei, M. (1988). Relationships between gene trees and species trees. Mol. Biol. Evol. 5: 568-583.

Penny, D., Foulds, L. R., and Hendy, M. D. (1982). Testing the theory of evolution by comparing phylogenetic trees constructed from five different protein sequences. Nature 297: 197-200.

Ragan, M. A. (1992). Phylogenetic inference based on matrix representation of trees. Mol. Phylogenet. Evol. 1: 53-58.

Rage, J .-C. (1987). F ossil history. In "Snakes: E cology and Evolutionary Biology" (R. A. Seigel, J . T. Collins, and S. S. Novak, Eds.), pp. 77-105, Macmillan, New York.

Rodrigo, A. G. (1993). A comment on Baum's method for combining phylogenetic trees. Taxon 42: 631-636.

Rodrigo, A. G., Kelly-Borges, M., Bergquist, P. R., and Bergquist, P. L. (1993). A randomisation test of the null hypothesis that two cladograms are sample estimates of a parametric phylogenetic tree. New Zealand J . Bot. 31: 257-268.

Savitzky, A. H. (1978). “The Origin of the New World Proteroglyphous Snakes and I ts Bearing on the Study of Venom Delivery Systems in Snakes," unpublished Ph.D. dissertation, Univ. Kansas, Lawrence.

Schwaner, T. D., Baverstock, P. R., Dessauer, H. C., and Mengden, G. A. (1985). I mmunological evidence for the phylogenetic relationships of Australian elapid snakes. In "Biology of Australasian F rogs and Reptiles" (G. Grigg, R. Shine, and H. Ehmann, Eds.), pp. 177-184, Royal Zoological Society of New South Wales, Australia.

Shine, R. (1985a). Ecological evidence on the phylogeny of Australian elapid snakes. In "Biology of Australasian Frogs and Reptiles" (G. Grigg, R. Shine, and H. Ehmann, Eds.), pp. 255-260, Royal Zoological Society of New South Wales, Australia.

Shine, R. (1985b). Theevolution of viviparity in reptiles: An ecological analysis. In "The Biology of the Reptilia," (C. Gans and F. Billett, Eds.), Vol. 15, pp. 605-694, Wiley, New York.

Slowinski, J. B. (1993). “Unordered" versus "ordered" characters. Syst. Biol. 42: 155-165.

Smith, H. M., Smith, R. B., and Sawin, H. L. (1977). A summary of snake classification (Reptilia, Serpentes). J . Herpetol. 11: 115-122.

Smith, M. (1926). Monograph of the Sea-Snakes. Oxford Univ. Press, London.

Strydom, D. J . (1979). The evolution of toxins found in snake venoms. In "Snake Venoms" (C.-Y. Lee, Ed.), pp. 258-275, Handbook of Experimental Pharmacology, Vol. 52, Springer-Verlag, Berlin.

Swofford, D. L., Olsen, G. J ., Waddell, P. J ., and Hillis, D. M. (1996). Phylogeny inference. In "Molecular Systematics" (D. M. Hillis, C. Moritz, and B. K. Mable, Eds.), 2nd ed., pp. 407-514, Sinauer, Sunderland, MA.

Swofford, D. L. (1997). PAUP*: Phylogenetic analysis using parsimony (* and other methods), version 4.0. Sinauer, Sunderland, MA.

Szyndlar, Z., and Rage, J.-C. (1990). West Palearctic cobras of the genus Naja (Serpentes: Elapidae): interrelationships among extinct and extant species. Amphibia-Reptilia 11: 385-400.

Takahata, N. (1989). Gene genealogy in three related populations: consistency probability between gene and population trees. Genetics 122: 957-966.

Tamiya, N . (1985). A comparison of amino acid sequences of neurotoxins and of phospholipases of some Australian elapid snakes with those of other proteroglyphous snakes. In "Biology of Australasian Frogs and Reptiles" (G. Grigg, R. Shine, and H. Ehmann, Eds.), pp. 209-219, Royal Zoological Society of New South Wales, Australia.

Underwood, G. (1967). "A Contribution to the Classification of Snakes,"Trustees of the British Museum, London.

Underwood, G., and Kochva, E. (1993). On the affinities of the burrowing asps Atractaspis (Serpentes: Atractaspididae). Zool. J . Linn. Soc. 107: 3-64.

Wu, C.-I. (1991). Inferences of species phylogeny in relation to segregation of ancient polymorphisms. Genetics 127: 429-435. 